\title{
Low use and high discontinuation of modern contraceptives in Pakistan: Reasons and policy recommendations
}

Population Council

Follow this and additional works at: https://knowledgecommons.popcouncil.org/departments_sbsr-rh

Part of the Demography, Population, and Ecology Commons, Family, Life Course, and Society Commons, International Public Health Commons, and the Women's Health Commons How does access to this work benefit you? Let us know!

\section{Recommended Citation}

"Low use and high discontinuation of modern contraceptives in Pakistan: Reasons and policy recommendations," Policy brief. Islamabad: Population Council, 2015. 
According to the latest Pakistan Demographic and Health Survey (PDHS 2012-13), 20\% of married women of reproductive age (MWRA) have an unmet need for contraception. Moreover, the country's contraceptive prevalence rate (CPR), for modern and traditional methods put together, is only 35\%-one of the lowest CPRs in the region. (PDHS 2013-13).

Unfortunately, the issue does not end here. In addition to the problem of non-use, the country is finding it difficult to keep current users of contraceptives on board: compared to other developing countries, Pakistan has the highest rate of discontinuation of contraceptive use. Thus, as the graph below shows, while there has been an overall increase in the use of contraceptives-both in modern methods as well as 'any,' i.e., both modern and traditional methods-there is a large difference between the ever use of any method and current use.

PDHS 2012-13 made the disturbing finding that more than a third of women who had started using a contraceptive method in the preceding five years had stopped using it within 12 months. One in every five of these women had discontinued due to methodrelated reasons, including side effects, method failure, dissatisfaction in use, lack of access, and affordability. According to Mahmood and Naz (2012), eliminating discontinuation due to side effects and method failure could increase continuation rates (at one year) in Pakistan by 10 percent and 6 percent, respectively.

This brief highlights the main sources of obstacles in family planning adoption and continuation, from domestic hindrances through issues of access to problems in service provision at facilities and beyond. The focus is on probing beyond traditional explanations with a holistic view to identify gaps in the demand for family planning care as well as its supply. We investigate not only the low use of contraceptives but also the alarmingly high rate of discontinuation. Policy recommendations are accordingly set forth.

\section{DATA SOURCES}

The extraction for this brief is based on the findings of a national level study carried out by the Population Council in 2014 to investigate the reasons for low modern contraceptive use in Pakistan. Data for the study was collected from eight districts ${ }^{1}$, including two from each of the four provinces, using a number of research tools that are outlined at the end of the brief.

Current Use of Modern and Traditional Contraceptive Use (1991-2013)

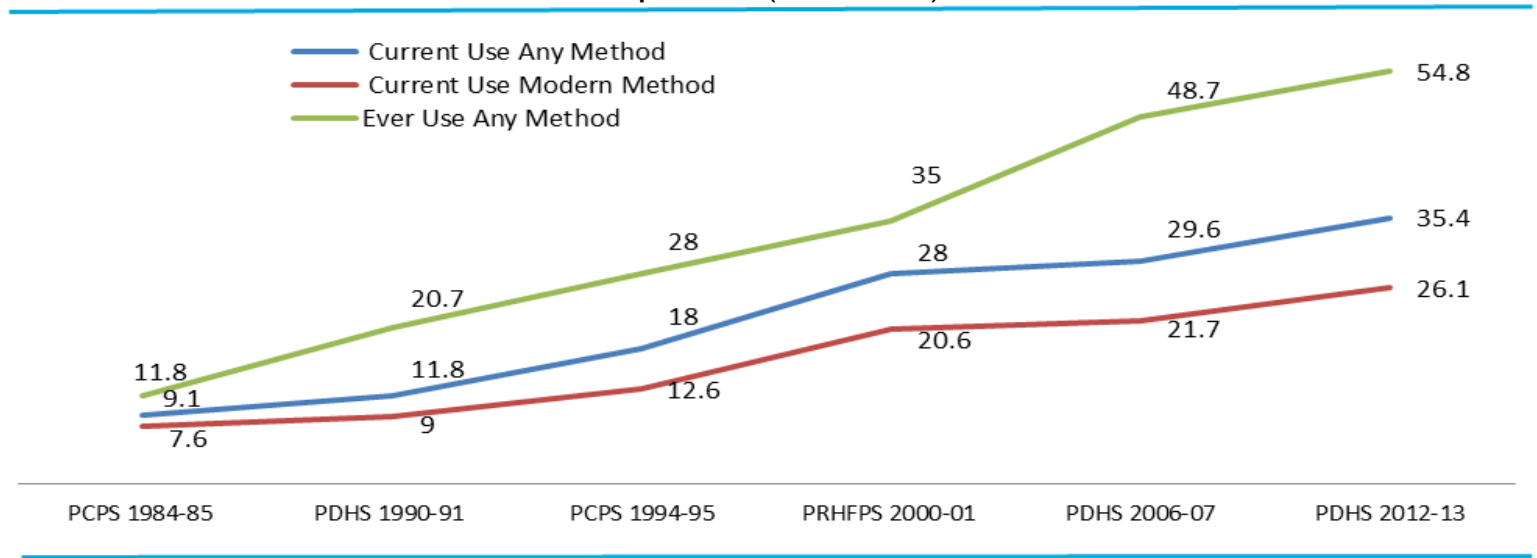

Sources: Pakistan Contraceptive Prevalence Surveys (1984-85, 1994-95), Pakistan Demographic and Health Surveys (1990-91, 2006-07, 2012-13) and Pakistan Reproductive Health and Family Planning Survey (2000-2001).

1 Khanewal and Rahim Yar Khan in Punjab; Khairpur and Umerkot in Sindh; Mardan and Mansehra in KP; and Pishin and Sibi in Balochistan. 


\section{HINDRANCES AT HOUSEHOLD LEVEL}

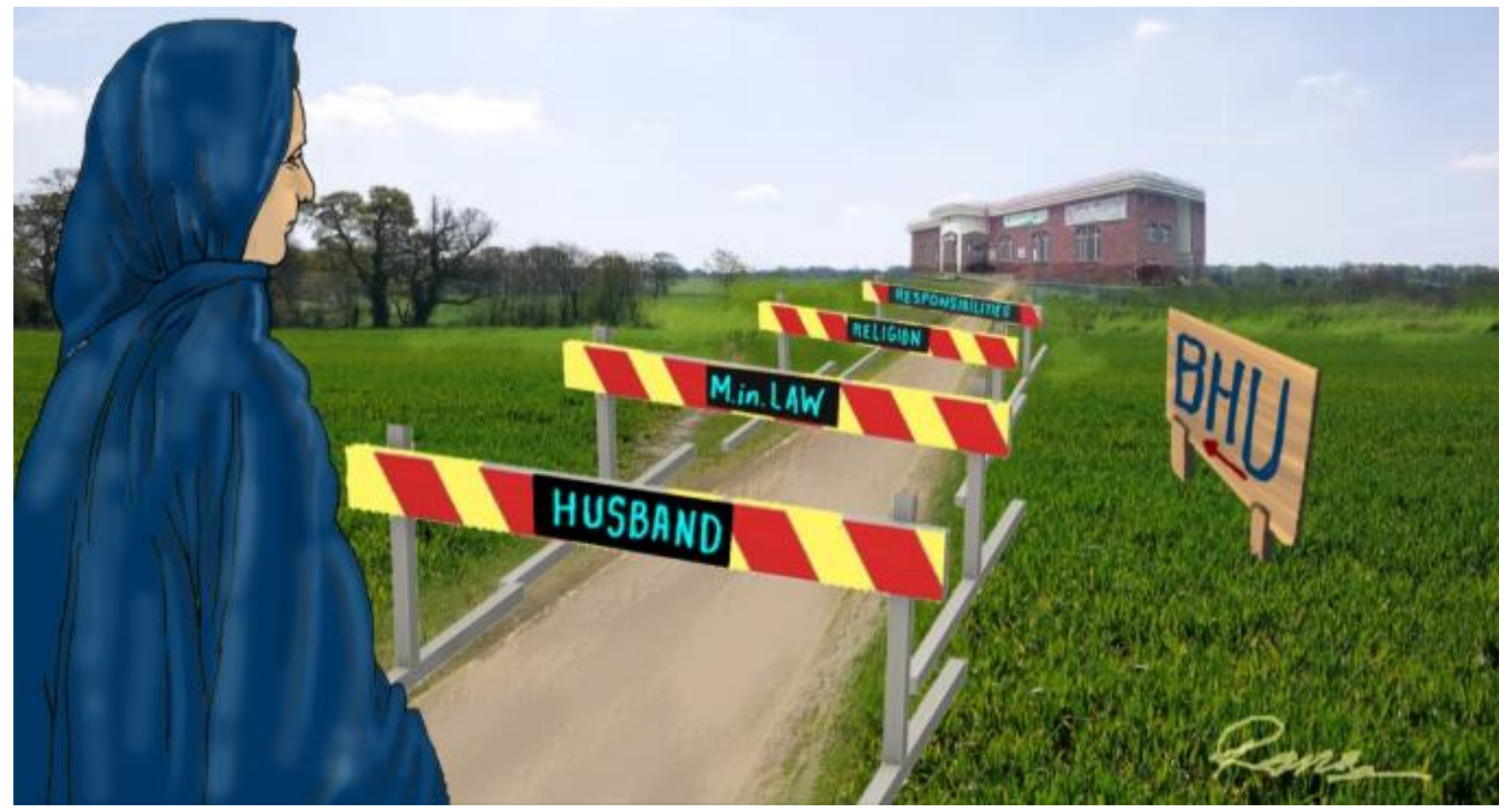

For most couples in Pakistan, the intention to adopt family planning originates at home and is affected by domestic circumstances. A woman may feel a need to use contraceptives, but be unable to fulfill it because her husband does not communicate with her about family planning, or is averse to it. She may be confused as to the religious acceptability of family planning, or her in-laws might forbid it altogether. However, recent studies indicate that such household-level obstacles to family planning adoption are on the decline.

\section{Role of the husband}

- $\quad$ The hindrance posed by husbands to family planning is waning in all provinces, particularly in Punjab and Sindh, where men are becoming more supportive of family planning, primarily because it can help avoid the economic burden of a large family.

- Communication on family size is taking place between all couples, regardless of where they reside, be it rural or urban. This is a positive development because when couples discuss their fertility intentions with each other, in the majority of cases, if not all, there is a possibility of convergence on the use family planning methods.

- However, these changes are as yet less pronounced in Khyber Pakhtunkhwa (KP) and Balochistan, where cultural factors retain a relatively stronger influence on the role of men. At times, husbands do not support their wives in adopting family planning because of societal and tribal pressures to 'prove their masculinity' by producing more children, particularly sons.
We thought about it [family planning] from the first child. Initially, I was very weak, and keeping my health in view, my husband decided to opt for family planning. He said if there were [too many] young kids it would be hard for me to take care of them; therefore we should have spacing between births. In this way, I would be able to take care of the house and raise them in a better way. This is how we thought through this decision to practice family planning.

Female current user, 30 , mother of 4 , in rural, unserved community, Khanewal

I think the husband's permission is a big problem. Like my husband didn't say it before, so I had three kids. Now, when my husband said it, I used the method. If my husband wouldn't have said it to me, I wouldn't have gotten the injection because, without the permission of the husband, women cannot even go up to the door of the house. So how can we go to the hospital?

Female current user, 26, mother of 3, in semi-urban community, Pishin 


\section{Role of other family members}

- In Punjab and Sindh, the influence of other family members on a couple's family planning decision-making is declining. Most of the time, the decision to adopt family planning is taken solely with the mutual understanding of the husband and wife.

- However, in KP and Balochistan, mothers-in-law still exert a strong influence on family planning decision-making, especially since they retain control over the mobility of women of the household. Being more traditional, they prefer a larger number of children, and are also more likely to listen to religious clerics who oppose family planning. In such cases, without the permission of the mother-in-law, it is difficult to adopt family planning.

\section{Role of religion}

- Religion is no longer the most significant factor in family planning decision-making and use. However, its inhibiting effect on contraceptive use has not vanished completely, particularly in KP, where it is still widely held that Islam does not allow family planning.

- Maulvis (religious clerics) spread the misperception that family planning is incompatible with Islamic belief and discourage its use. They also encourage large families, claiming, for instance, that women with more children are worthier in the sight of God and will be rewarded with Paradise. These emotional appeals affect people and are followed by disapproval of those who practice family planning.

\section{Household responsibilities}

- The heavy workload of women in large households takes up the better part of their day, leaving little time for them to avail family planning services.

- Women living in rural unserved areas, are especially affected by household work-load, since they have to take out a full day to visit a health provider, who is often located far away.
I don't talk to anyone else except for my husband. Then it is up to him to listen. We discuss with each other before taking any step.

Female never user, 27, mother of 5 , in rural, unserved community, Khanewal

The husband, mother-in-law and the father-in-law don't agree. They say, don't take the daughter-in-law anywhere [for family planning] and (she should) produce a baby every year because we want more boys and those families who have a large number of boys are considered as the strongest here. They want a son every year, whether the daughter-in-law lives or dies.

Female past user, 30, mother of 3 , in rural, unserved community, Pishin

No, if you see, in Islam, there is permission for family planning. It is written in the Quran that you breastfeed the children for two years-then those two years should be considered as birth spacing. Recently, on TV, they were saying how the Quran and Sharia allow birth spacing. It is not a sin to do family planning according to Quran and Hadith.

Female current user, 30 , mother of 4 , in unserved community, Khanewal

No, they were not saying such a thing on their own. There is a religious cleric in our neighborhood who tells the people that the woman or the man who put a stop to having children, they are both sinners and they will be punished.

Female never user, 35, mother of 3, in urban community, Mansehra

I told my husband to take me for the operation but we did not go as we didn't get time for it, and by the time we did, I had conceived and had a baby boy. The reason was that I was busy in my housework; I didn't get time. I was always stuck due to housework, looking after cattle, etc...It is very hard for women to leave the houses.

Female past user, 42 , mother of 7 , in rural served community, Khairpur 


\section{PROBLEMS IN ACCESS}

After overcoming the household-level issues that hinder their use of family planning services, women have to face another set of hurdles in accessing family planning services. The key issues are distance from services, transport problems and travel cost; timings of facility; and availability of female service providers.

\section{Distance}

- Physical access to services is a real challenge, especially for women who live in rural unserved and remote areas. In unserved areas of Balochistan and $\mathrm{KP}$, the rugged terrain and scattered settlement pattern further exacerbate the problem.

- $\quad$ Distance from family planning services implies a number of difficulties. For a starter, distance compounds household-level hindrances-more time needs to be taken out from household chores; it is harder to ignore traditions against female mobility; and, consequently, husbands and mothers-in-law may be less supportive. In addition, distance implies a need for transportation, which may or may not be available, and significant expenditure on travel costs.

- As the map below shows, a woman living in an unserved community of Sindh may have to travel 36 kilometers (or even further) to reach the nearest facility. On the other hand, women in served communities usually do not have to face this problem; they can usually reach health services at a number of public and private facilities within a radius of 5 to 15 kilometers.

- Long distances between homes and facilities discourage women from seeking family planning services. The number and intensity of hurdles they face increase in direct proportion to the distance they have to cover. Finding no facility available within even a 10- or 15-kilometer radius, women from disadvantaged traditional backgrounds are likely to give up their intention to use family planning on account of distance alone. Only the most determined would be ready to brave the difficulties of travel.

Map: Distance between selected study communities and the nearest public and private health facilities

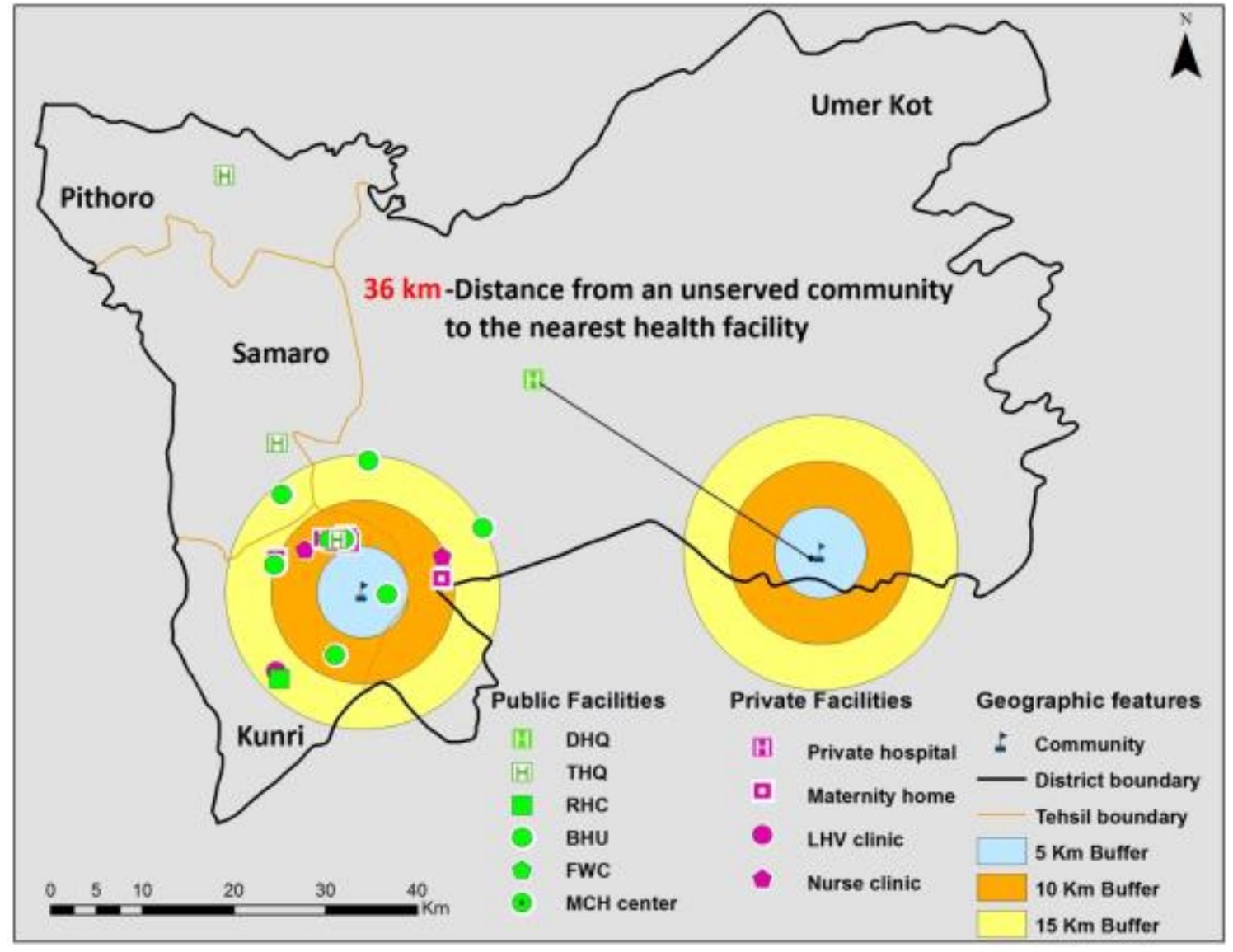


- Lack of transportation means prevents men and women from using family planning services, even when they desire to, particularly in KP and Balochistan.

- In remotely located communities, transportation is frequently not available; sometimes, people have to travel to facilities on foot or on donkey carts.

Travel Cost

- Where transportation is available, the next hurdle to surmount is travel cost. Financial constraints can prevent willing men and women from using family planning methods, particularly in unserved remote areas, where the longer distance translates into higher travel costs. Ironically, residents of these areas often face the greatest poverty and the highest unmet need for family planning.

- Although fares for public transport are generally low, they can add up to an unaffordable amount for poor users: women cannot travel alone (owing to cultural restrictions), and the cost of a round trip for at least two people can be prohibitive.

\section{Working Hours of Facilities}

- The working hours of health facilities play an important role in determining whether they are accessible to visitors. Public health facilities often maintain short working hours, which minimize the time window available to users to access services. This is a serious concern in rural areas, where the heavy workloads, restricted mobility and lower availability of transportation can make it nearly impossible for women to reach facilities before 2:00 PM, when the facilities close.

- Rural health centers (RHCs) are mandated to provide round-the-clock services seven days a week. However, far from working $24 / 7$, nearly half of the RHCs do not even provide services in the afternoon evenings (i.e. after $2 \mathrm{pm})$.

- In the evenings, far more private sector facilities are available to meet family planning needs than public sector facilities. However, not everyone can afford private care.
For this [family planning] method, you need to go to the city. Who would go till there? There should be a [means of] transport for going till there. But we don't have anything.

Female focus group discussion (FGD) participant from a rural, unserved community in Pishin

I told you about the financial conditions: that on one side, there is poverty, and on the other hand, the hospital is 10 or 12 kilometers away. So, for this reason, using these methods is out of our range.

Male never user, 34, father of 3, in rural, unserved community, Mardan

A person who wants to use a method worth 6 rupees has to spend 65 rupees on transport. When facilities are available locally, it saves time as well as travel costs.

Male interviewee from an unserved community in Punjab

\section{$47 \%$ RHCs} do not provide services in the evening session 


\section{Quest for Family Planning}

A Rural Woman's Journey to a Health Facility

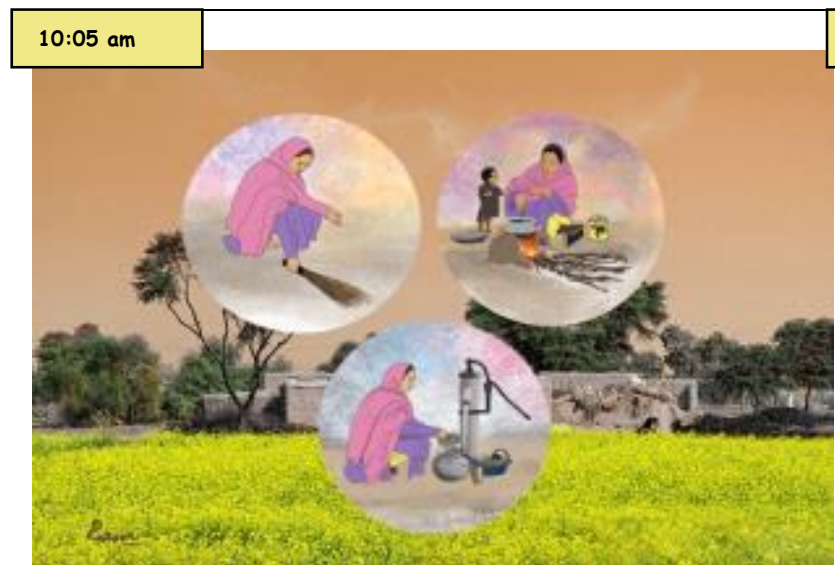

I MUST SEE THE DOCTOR TODAY! WE CAN'T AFFORD ANY MORE BABIES. AND I ALSO NEED TO GET THAT BLEEDING CHECKED...IT'S BABIES. AND I ALSO

(BUT IDD BETTER FINTSH UP ALL THESE CHORES FTRST OR THEYLL GIVE ME NO PEACE...)

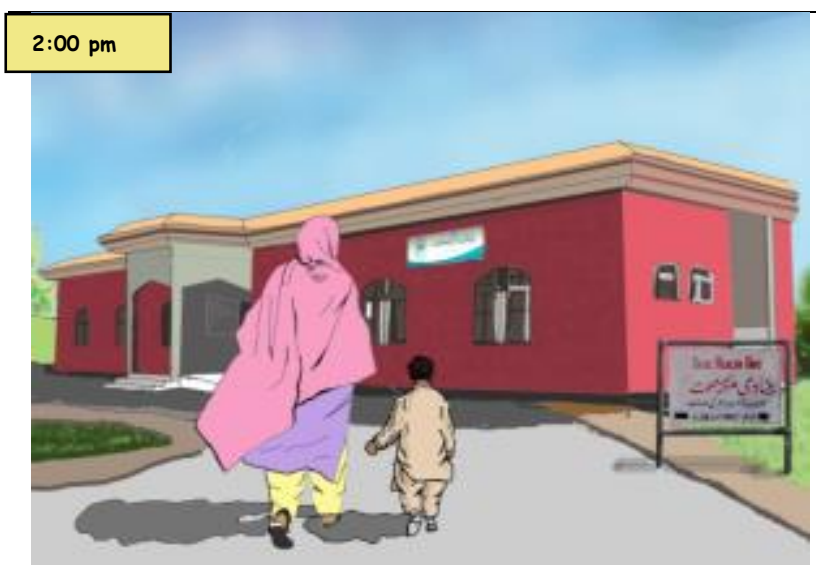

AT LAST! HOW MY LEGS HURT AFTER THAT LONG WALK FROM THE STOP! THAT DRIVER CERTAINLY TOOK HIS TIME, BUT THEN THE ROADS WERE SO BAD.

OH PLEASE LET THE DOCTOR BE THERE! ANY MORE DELAY AND I'LL BE PREGNANT AGAIN.

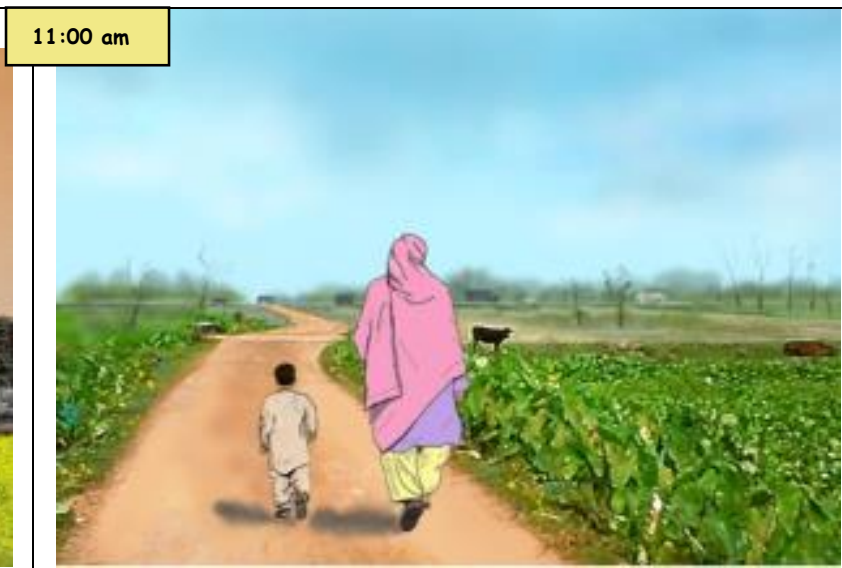

TOO BAD HE COULDN'T GET AWAY FROM WORK TODAY - I HAVE TO MAKE MY POOR BOY MISS SCHOOL. WISH I COULD JUST GO TO THE CLINIC BY MYSELF BUT I'M A WOMAN

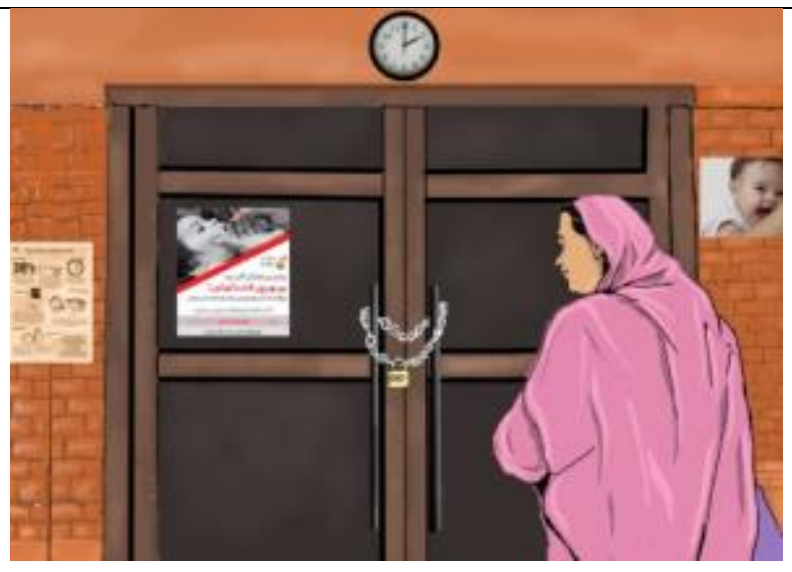

\section{$\mathrm{OH} \mathrm{NO}$}

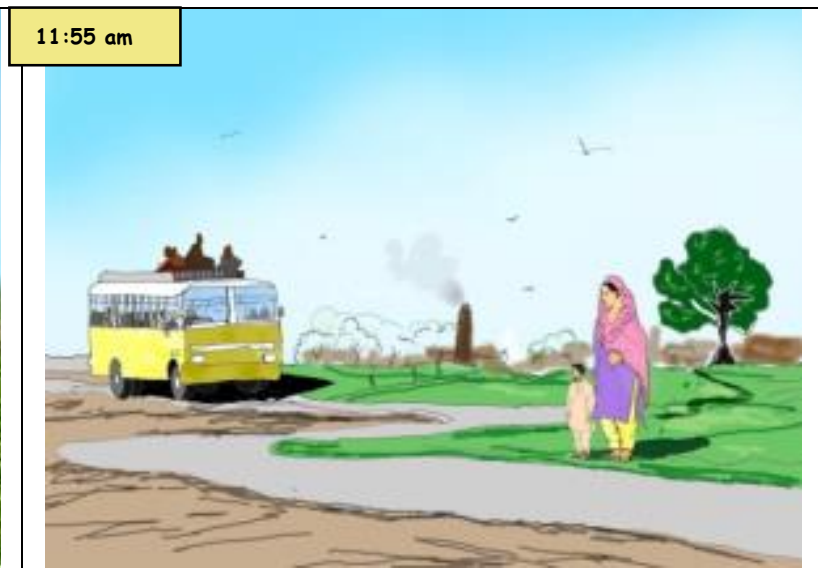

JUST IN TIME! THANK GOD I DIDN'T MISS IT, OR I'D HAVE HAD TO COME AGAIN TOMORROW... HOPE THEY HAVEN'T RAISED THE FARE. I JUST BARELY HAVE ENOUGH IN MY PURSE.

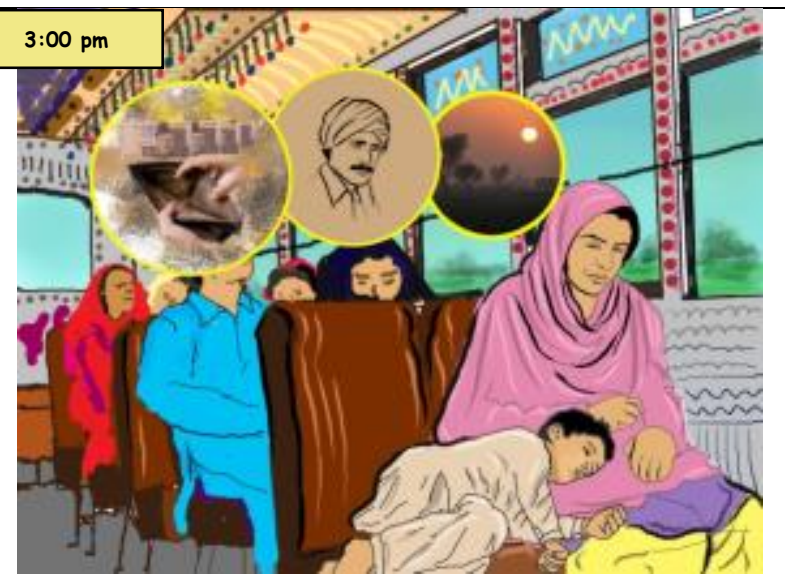

ALL DAY WASTED ALL THAT MONEY DOWN THE DRAIN HE'LL BE SO ANGRY WITH MEI "YOU THTNK WE HAVE MONEY TO THROWI?" HE'LL SHOUT.

I'M SICK. I'M TIRED. I CAN'T KEEP DOING THIS ALONE. MAYBE IT IS GOD'S WILL THAT WE HAVE MORE CHILDREN. 


\section{Availability of Female Service Providers}

Access to family planning services is closely linked with the availability of female service providers at health facilities, since social norms do not allow women to discuss sexual health matters with male providers.

- Lady health visitors (LHVs) are the most available cadre for catering to women's family planning needs at all types of public health facilities. This cadre is available at $100 \%$ of DHQ and THQ hospitals, and of $91 \%$ at RHCs. However, LHVs are also the cadre most likely to be overburdened.

- Women Medical Officers (WMOs) are far less available than they should be. As the table below shows, a large

Some women that come to our health center arrive around 2:00 p.m., when they are done with their housework, and we also have to leave about this time. So we tell them to come the next day. But by the time they come again, they have already conceived. But we always try that whosoever comes to the health center takes a method.

LHV at a public sector THQ hospital in Umerkot proportion of sanctioned posts for WMOs are currently vacant at all types of public health facilities. This leaves health facilities with a gap in provision of female providers as well as technical expertise.

Women Medical Officers Posts, \% Vacant

$\begin{array}{ll}\text { DHQ hospitals } & 28 \\ \text { THQ hospitals } & 69 \\ \text { RHCs } & 46\end{array}$

There is no facility there. This is why, mostly, people cannot use contraceptives. Secondly there are no lady doctors. Women cannot talk openly to men.

Female past user, 25, mother of 2 , in semi-urban community, Sibi

\section{Timings and availability of female service providers}

- In the public sector, female service providers are mainly present in the morning sessions and their presence shrinks to a minimal level of only $20 \%$ in the evening sessions.

- Availability of WMOs at RHCs is a serious concern, even in the morning session. As the above table shows, nearly half of the posts for WMOs are vacant.
The hospital is far away and the doctor also comes infrequently, and when she does come, she comes for a very short time. And then she goes away and we don't get the medicine for free. Whenever a woman, after doing her work, goes to the hospital, it takes a lot of time on the way and when she gets to the hospital, the rooms are closed. And she can't see anyone in the hospital.

Female FGD participant from a rural unserved community in Pishin

- Service providers are often absent from duty, or they come for a short period and leave early. This issue is most frequently seen in Balochistan.

- Given the hurdles they have to overcome to reach health facilities in the first place, it is extremely discouraging for women to find, upon reaching the facilities, that they are closed or no female service provider is available. Such a woman might be asked to visit again the next day, but it is highly unlikely that she will be able to return, even if she wants to. 


\section{Proportion of Facilities with at least One Female Service Provider Available}

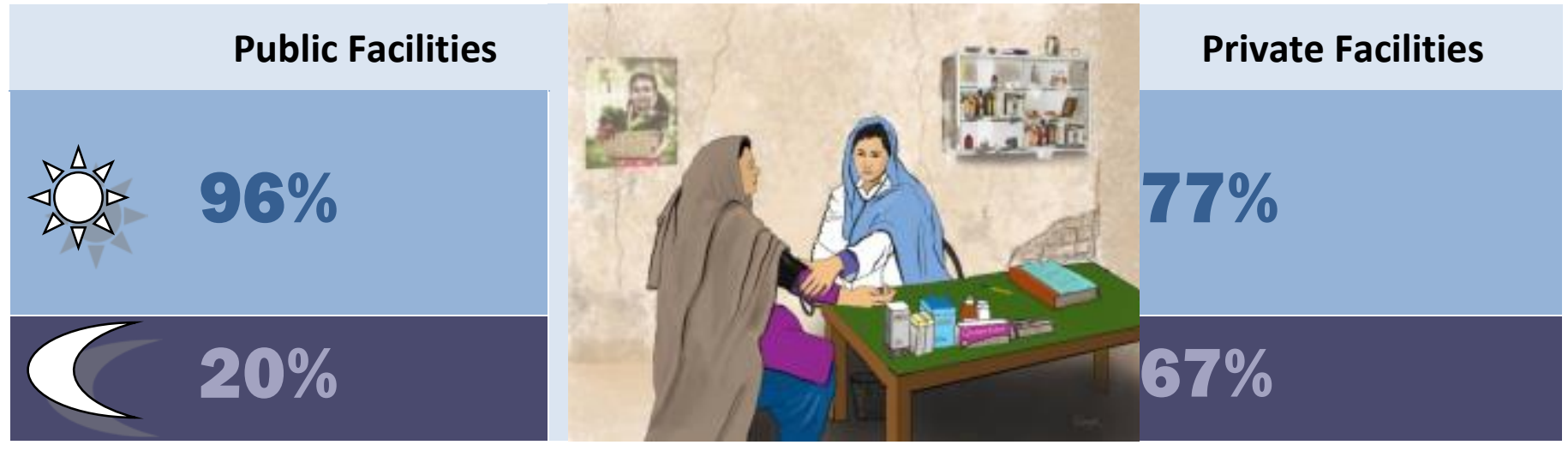

\section{QUALITY OF CARE \& SERVICE DELIVERY}

As the foregoing discussion indicates, being able to leave her home to seek family planning services, managing to reach a health facility while it is open, and finding a female service provider on duty can be quite difficult a woman in Pakistan, especially when she resides in a rural unserved area. However, coming this far does not guarantee that her needs will be met. The next important determinant in whether or not she can adopt, or continue to use, a family planning method is quality of care, which encompasses a range of variables, including but not limited to the knowledge, skills and behavior of service providers.

- At public facilities, the behavior of service providers with clients can be lacking in courtesy and respect, which discourages women from visiting.

- For new acceptors, information about possible side effects of specific contraceptive methods, and the way they should be managed, is crucial to allay initial fears and avoid early discontinuation. A follow-up visit should also be scheduled for the same reasons. However, currently, most service providers do not consider it important to provide complete information to new users of contraceptives, or to schedule follow-ups. 


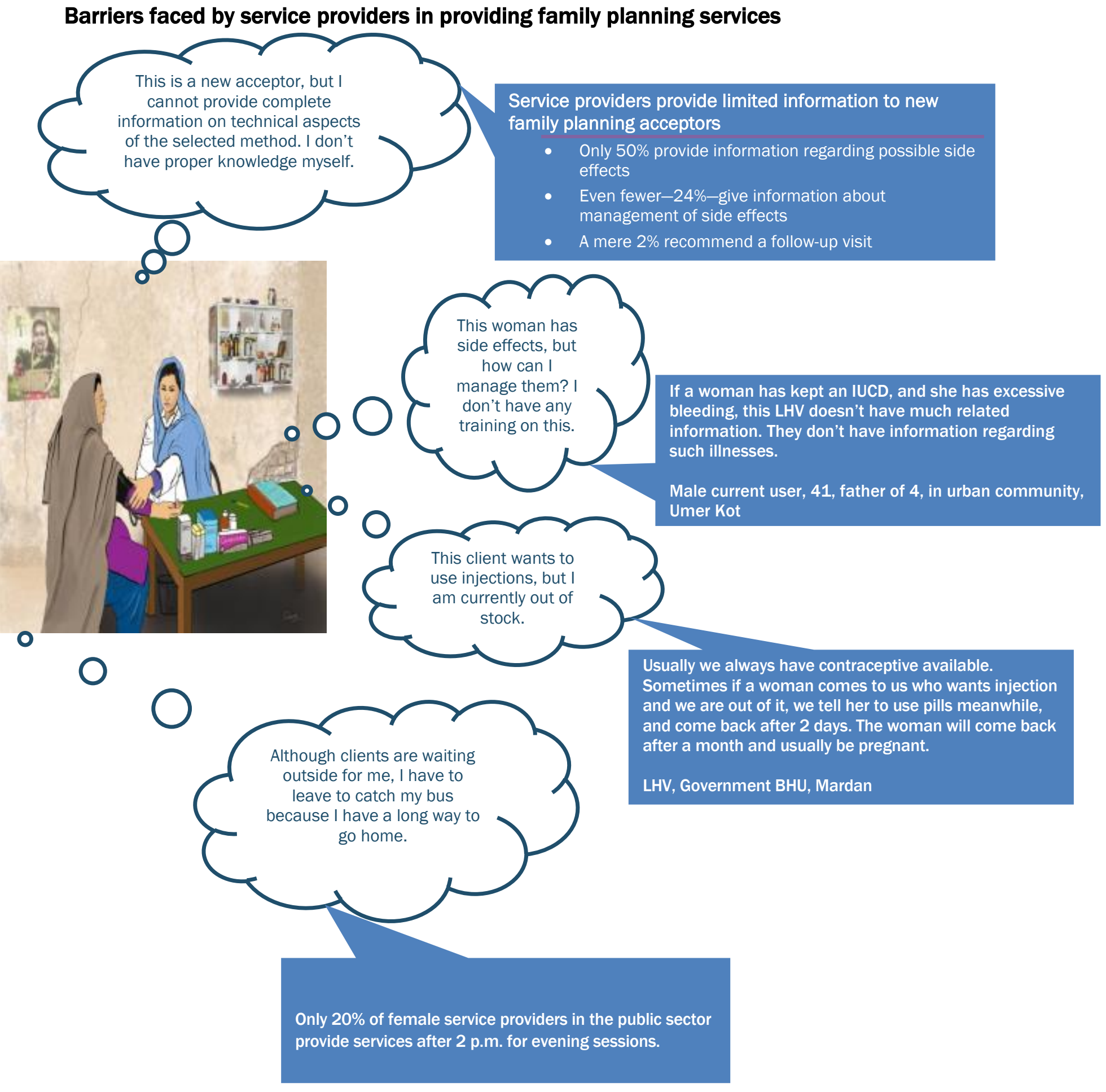




\section{Public vs. Private Care}

- The private health facility providers are generally ranked better by clients than those working in the public sector in terms of their behavior, particularly the way they greet and treat their clients.

- In the private sector, service providers are better informed about the range of contraceptives their proper usage, and possible measures that can be taken to deal with side effects.

- In the public sector, providers are overburdened with long queues of waiting clients; therefore consultations are hurried and clients are not able to get all their queries answered.

The government has opened a clinic but they don't look after the clients. One said that we came back after sitting there but no one asked us whether we want to have a checkup. Special attention should be given to women. The lady doctors push women out and say to come to our private clinic as we don't want to check you here. Yes, in their private clinic, they do check up properly but they do it for a fee.

Female current user, 28, mother of 4, in semi-urban community, Rahim Yar Khan

- Despite the shortcomings of the public sector facilities, people belonging to lower income strata are forced to visit them since they cannot afford the fees of private providers.

\section{AVAILABILITY OF CONTRACEPTIVES}

Although it is a basic and obvious prerequisite for family planning uptake and continuation, availability of contraceptives is, unfortunately, far from assured at all health facilities. Many service providers narrate how stock outs of various contraceptives force their family planning clients to go home empty-handed.

- Availability of contraceptives is not an issue for facilities associated with the Population Welfare Department. They usually have adequate stocks of all four standard contraceptive methods (i.e., condoms, pills, injectables, and IUCDs).

- However, in general, public sector facilities associated with the Department of Health suffer from frequent and prolonged shortages of all four methods. There is no single method out of the standard four that is available at all health facilities.

- Public DHQ hospitals have the least availability of contraceptive methods. This seems to be an administrative issue. DHQ hospitals are not under the jurisdiction of the EDO-Health but the Medical Superintendent in charge of the hospital. Medical superintendents neither request contraceptive supplies from the EDO-Health nor submit any separate requisitions for contraceptives to the Central Warehouse $(\mathrm{CWH})$, which supplies all public-sector district stores.

- Availability of IUCDs is very low, as the table on this page shows. This is a serious concern, especially in view of the growing programmatic interest in offering postpartum IUCD insertion as a standard protocol at health facilities.

- In addition, the situation of availability of the complete IUCD kit is alarming in both the private as well as the public sector: 71 percent of public and private health facilities do not have this kit. More than half of the facilities do not even have the essential IUCD kit available.

- For more than half the population, the available choice of contraceptive methods is severely limited. All four methods were found to be available at only $33 \%$ of facilities in Balochistan, $50 \%$ of facilities in KP, $51 \%$ of facilities in Sindh, and $\mathbf{5 3} \%$ of facilities in Punjab.

- Large stocks of IUCDs and injectables remain unutilized at RHCs.

$67 \%$ of RHCs have stocks of IUCDs

$73 \%$ of RHCs have stocks of injectables

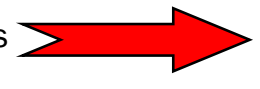
...but only $7 \%$ report IUCD dispensing ..but only $13 \%$ report injectable dispensing 


\section{Lady Health Workers}

The Lady Health Workers (LHW) Programme has helped to eliminate many of the obstacles faced by rural women and men in accessing family planning services. However, many of the quality and contraceptive availability issues found at static facilities are also reflected in the services offered by LHWs.

\section{People's perceptions of LHWs}

- $\quad$ LHWs provide doorstep services, so it becomes very easy for women who would not otherwise be able to access health services to utilize them.

- LHWs have a restricted choice of methods available, the most common ones being pills and condoms.

- Each LHW is required to cater to a large population. Therefore, she may not be able to address all concerns of every client. This issue also limits her ability to provide counseling services. Clients cannot receive satisfactory services most of the time.

- LHWs do not have sufficient training to manage the side effects of contraceptives.

- In Balochistan, the LHW is sometimes not from the local community (due to a lack of qualified women), and the transportation difficulties she faces, especially in the rural areas, which lack infrastructure, mean she is not able to visit often enough. This is a major obstacle in the utilization of family planning services by the local population.

The services are also provided at the BHU and the LHW also provides them. The LHW goes to all the houses and provides the services there and refers [women] to the BHU for the injection. LHW has a good attitude towards people when she goes to their homes. Good attitude is also present when she refers someone to the BHU. She provides the pills and condoms at home but for the injection she gives a receipt or a token for getting the injection at the BHU. Quality, services and attitude is very good.

Male current user, 45 , father of 3 , in rural served community, Mansehra

There is no system of family planning here. The men don't know, neither do I know. We people have found out a little bit now...If there are LHWs, they don't come. There are no services. LHWs don't have transport. They do not belong to the village. If they were educated in the village then everyone would have the services. Neither is there any educated person in the nearby village nor in our own village.

Male interviewee from a rural community in Sibi

\section{Key issues faced by LHWs}

- There is frequent shortage of contraceptive stocks and disruption in supplies. During stock-outs, LHWs usually manage by borrowing from other LHWs or by referring clients to a health facility.

- Deficiencies in the contraceptive stocks of LHWs reduce the utility of Health Houses (house of a LHW).

- LHWs particularly from Balochistan and Sindh have fewer options in their available method mix, having less availability of all three methods, pills, injectables and condoms

It has been one year I did not get condoms. Pills and injections were not available for three months. In such scenario, I usually ask the women to get the contraceptives from city or I would go to the city myself to buy these injections/pills and then would give them to the women in my area

\section{LHW-Rural-Khairpur}

My stock finished two times in the past 2 years, once for 2 weeks and then once for 12 days. I used to tell the clients that I do not have the supply. I used to contact the office people and get the stock from another hospital. If I get it from another hospital then I don't take money and if I get it from a medical store then they pay me.

\section{LHW-Semi Urban-Pishin}

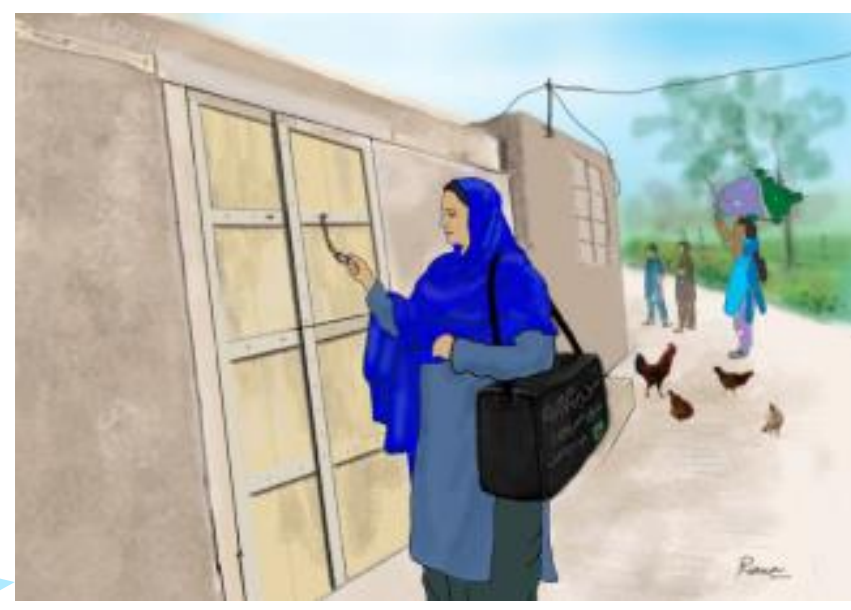




\section{DISCONTINUATION \& SIDE EFFECTS}

Our study finds discontinuation to be driven mostly by perceptions and experiences of side effects of modern contraceptives. Women and men from communities as well as service providers list method-specific side effects that plague users, forcing them to switch methods, turn to traditional methods, and, at times, finding none safe or useful, opt out of family planning altogether. Efforts of couples to get help in managing side effects are frustrated by the same household-level hindrances, access problems and care quality issues that make it difficult to obtain family planning services in the first place.

- Women are discontinuing because of side effects even in semi-urban and urban areas, where presumably there is relatively better access to healthcare providers.

- Side effects are experienced more for injectables and IUCDs. Apart from the actual side effects, fear of side effects and the personal, social and economic costs of living with side effects also force women to discontinue contraceptive use.

- Heavy bleeding has been reported as the major side effect of contraceptives, which in turn leads to inability in performing household chores, taking care of children, offering prayers, maintaining marital relations, attending social gatherings, and managing the cost of side effects.

I took contraceptive pills for three months. I had bleeding three times a month. My body shrank. I stopped taking pills after that. This was the reason, nothing else. I had such an illness that nothing could give me any relief. I used to take them and when I left the pills, the bleeding stopped.

Female FGD participant from semi-urban community, Rahim Yar Khan

We used injections for the first two years, but they caused a lot of problems. Periods started again and again, my wife remained sick often, even marital life was affected to some extent. And, secondly, the children were young and they were not being given proper upbringing. And my wife's health was getting worse day by day. Another problem was that my financial condition was getting very bad as we had to go to the doctors for the treatment again and again. Whatever I earned I spent it on the treatment of the disease. There was not just the disease in the house that had to be taken care of; there were other needs too, like food and other expenditures. Other than this she couldn't go to any relatives' house to take part in the happiness or grief of family life. That is why we stopped using the injection; after leaving the injection, conditions returned to normal.

Male past user, 35 , father of 2 , in served community, Mardan

\section{Side effects feared or experienced by women and men}

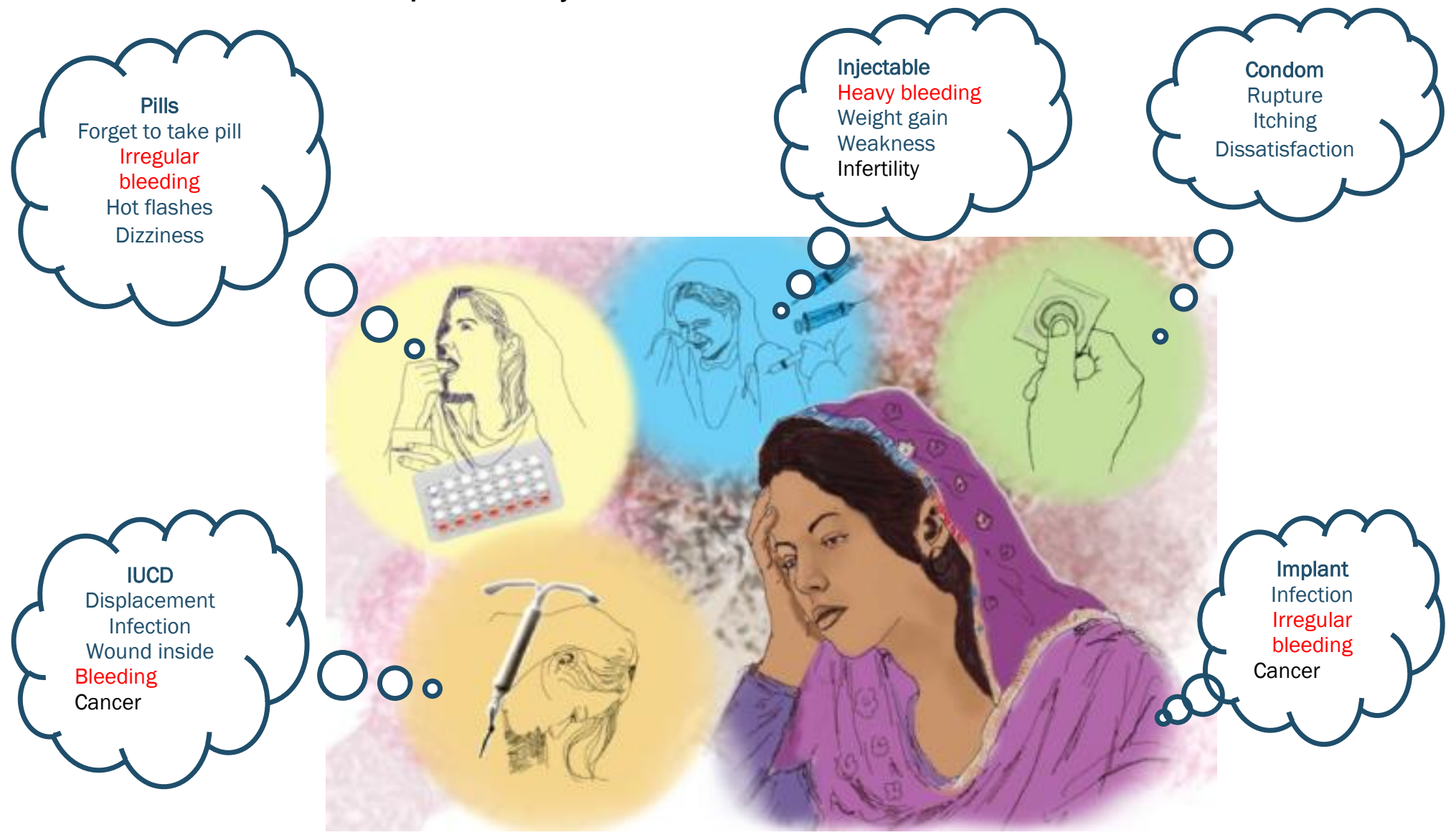




\section{PROVINCIAL DIFFERENCES}

- With respect to household hindrances and access difficulties, the problems are much more severe in Balochistan and KP than in Punjab or Sindh.

- $\quad$ Religious clerics continue to exert a negative influence against family planning in KP. Persuaded by them, husbands and mother-in-laws discourage women from using contraceptives.

- Physical access is most difficult in Balochistan, due to the scattered population and large distances from facilities. It is also a challenge in KP, parts of which are rugged and prone to landslides.

- $\quad$ Choices in contraceptive methods are very limited at Department of Health facilities, especially in Balochistan.

\section{RECOMMENDATIONS}

\section{Improving Accessibility}

\section{At community level:}

- Coverage in under- and unserved areas should be increased by delivering services at the doorstep through LHWs or other community-based workers, such as community midwives (CMWs).

- $\quad$ The role and status of LHWs should be extended and expanded by increasing the pool of LHWs, and appointing more LHWs in under-served and unserved rural areas.

- $\quad$ Already serving LHWS need to make regular visits to their assigned communities; the burden of other duties should be reduced so they can focus mainly on providing family planning services.

- Unserved, especially distantly located, areas with a scattered population can be served through regular visits of mobile service units to address family planning needs of men and women.

- Under-served areas in remote and rural parts of districts, particularly in Balochistan (where community based LHWs are hard to identify), should receive family planning services using diverse strategies, such as mobile provider services and regular camps.

- Men from conservative pockets should be contacted directly through group meetings and male health workers.
- Availability of services, infection prevention, management of side effects, range of contraceptives available, stock of complete and essential IUCD kits and behavior and counselling services are those issues that are faced by all provinces, including Punjab.

- In Sindh, LHWs often lack stocks of all three methods, which further reduce choices for clients.

- Local religious leaders should be involved and sensitized on family planning and then involved in family planning campaigns so they can tell local people about the importance of birth spacing in a religious perspective.

- Regular provider visits to distant communities should be arranged to boost uptake of family planning methods. A schedule identifying the days, times and durations of such visits should be scheduled for an entire year, and be available at key locations in the communities to be visited.

\section{At health facility level:}

- Availability of human resources, especially trained female service providers of family planning services, should be ensured at all levels of health facilities.

- Under-utilized health facilities should be made operational/functional by deputing staff and ensuring that official timings are properly observed.

- RHCs should provide services $24 / 7$ in all provinces as per their mandate; issues of availability of female service providers need to be addressed by providing them with incentives.

- In case of non-availability of female service providers, existing male service providers, particularly skilled dispensers, can be trained in family planning to serve the needs of local people.

- All sanctioned posts should be filled. 


\section{Improving Quality of Care}

- The untapped potential of RHCs needs to be exploited by filling the posts for Women Medical Officers, and ensuring these facilities provide round-the-clock services every day of the week as per their mandate. This is necessary to maximize utilization of family planning services.

- $\quad$ Trainings and refreshers of all female staff including doctors, WMOs, LHVs should be conducted on a regular basis to fill the gaps in technical knowledge and skills of providers and improve their capacities to better counsel patients and manage side effects.

\section{Improving Stock Availability}

- $\quad$ Like other facilities, DHQs should also have a regular and formal arrangement to ensure availability of contraceptives to meet the family planning needs of all potential clients and avoid missing such opportunities.

- $\quad$ Forecasting of contraceptive stock requirements should be done jointly with the service providers at health facilities to take into account ground realities.

- There should be a focus on ensuring availability of the full range of contraceptives to ensure that no client fails to adopt a method or is forced to discontinue use of a method because his/her preferred method is unavailable.

- $\quad$ Stocks should be supervised by checking availability against delivery status.

- IUCD insertion kits with associated facilities, such as infection prevention measures, should be made available.

- $\quad$ All health sector facilities need to be stocked with contraceptives to avoid missing opportunities to facilitate current and potential users.

- LHWs should never run out stock, for the basic three methods they already supply.

- $\quad$ Service providers, including LHWs, should have the complete method mix available to enable clients to make informed decisions and choose their preferred method of contraception.
- LHWs should also receive trainings to strengthen their technical knowledge, and their scope should be expanded to deal with initial side effects at least.

- Behavioral trainings of service providers should be conducted so that clients feel supported and leave facilities satisfied.

- It should be made mandatory for female service provider to provide counseling on family planning to potential clients during antenatal, natal and postnatal checkups, as well as general health treatments. Within a health facility, a separate desk can be set up for counseling, and an LHV can be appointed to ensure no woman leaves the center without receiving counseling services.

\section{Addressing Discontinuation}

- $\quad$ Skilled and trained providers should be available at health facilities to provide proper counseling at the time of method adoption to inform women about possible side effects.

- Myths and fears concerning the use and side effects of specific contraceptive methods should also be addressed in counseling.

- Strong communication campaigns should be launched to address method-related apprehensions of men and women. Male and female group meetings at community level can be a good practice for such campaigns.

- Providers should be trained in management of side effects.

- LHWs should be trained to strengthen their knowledge and skills, and enable them to treat initial side effects.

- LHWs should be equipped with full stocks of contraceptives, especially injectables and Emergency contraceptive Pills to avoid women becoming discontinuation cases. 


\section{Data Sources:}

\section{Qualitative Data}

- 56 in-depth interviews (IDIs) with women from rural served, unserved and semi urban communities

- 33 in-depth interviews (IDIs)

- 64 in-depth interviews (IDIs) with services providers from public and private static health facilities

- 24 in-depth interviews (IDIs) with Lady Health Workers from randomly selected communities

- 32 focus group discussions (FGDs) with women ( one in each community) rural unserved, rural served, semi urban and urban areas ( 272 women)

- 24 focus group discussion with men (one in each community) rural unserved, rural served, semi urban and urban ( 256 men)

- 7 focus group discussions with LHWs (one in each district) total 60 LHWs

\section{Quantitative Data}

- 185 health facilities were interviewed to know about infrastructure, amenities, equipment, availability of staff and contraceptive stock

- 230 Service Providers from 185 health facilities were interviewed to assess their knowledge and skills

- 455 interactions of service providers with clients were observed to assess quality of interactions using Observation guides

- 436 clients who had interaction with service providers were interviewed to know about their perception regarding quality of interaction

- 23 randomly selected LHWs were also interviewed to assess their knowledge and skills

\section{References}

1. Kamran,I. Tasneem,Z. Parveen,T. \& Zaidi,Y. Z. (2015)

"Investigating low modern contraceptive use in Pakistan" Population Council, Islamabad.

2. Rashida,G. Kamran,I. Muhammad,K. Niazi, R. \& Parveen,T. (.2015) "The availability and quality of family planning services across 8 districts in Pakistan" Population Council, Islamabad.

3. Population Council (2014) “Prioritizing Family Planning for Achieving provincial Maternal Child Health and Development Goals". Population Council, Islamabad.

4. Mahmood, A. \& Naz, S. (2012). "Contraceptive Use dynamics in Pakistan 2008-09". Population Council, Islamabad.

\section{- POPULATION COUNCIL \\ Ideas. Evidence. Impact.}

House 7, Street 62, F-6/3, Islamabad

Phone: 051-8445566 Fax: 051-2821401

Info.pakistan@popcouncil.org

www.popcouncil.org

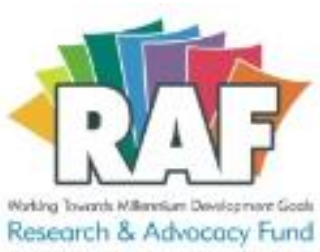

